\title{
Influence of Electropulsing Treatment on the Solidification and Heat Transfer Behavior of Mold Flux
}

\author{
Guomin YING, ${ }^{1,2)}$ Wanlin WANG, ${ }^{1,2) *}$ Haihui ZHANG, ${ }^{1,2)}$ Jie ZENG ${ }^{1,2)}$ and Lejun ZHOU ${ }^{1,2)}$ \\ 1) School of Metallurgy and Environment, Central South University, Changsha, Hunan, 410083 China. \\ 2) National Center for International Research of Clean Metallurgy, Central South University, Changsha, 410083 China.
}

(Received on August 4, 2018; accepted on November 2, 2018)

\begin{abstract}
An Electropulsing-assisted Mold Flux Heat Transfer Simulator technique (EPMFHTS) has been developed in this article, through which the pulsed electric current was applied to the molten mold flux pool during the initial solidification process in the continuous casing mold. The aim of this study is to investigate the effect of pulsed electric current on the mold flux crystallization and heat transfer behavior in the casting mold. The results suggested that the general variation trend of the responding temperature and heat flux were nearly same, which were divided into four stages, namely, rapidly rising, sharp declining, gradually declining and relatively stable. The temperatures and heat fluxes showed a faster reduction rate in the declining stage and their steady state values are lower under the Electric Pulse treatment (EPT) condition due to the increase of the thermal resistance resulted from the enhancement of the crystallization of the mold flux. The interface thermal resistance at the mold/slag film interface and the total thermal resistance of the slag film increased due to the improved crystallization through the accelerated particles movement resulted from EPT. The SEM image showed a larger crystalline fraction, thicker crystalline layer and smaller grain size under EPT, indicating that the EPT did promote the molten mold flux crystallization and refine crystals size in the continuous casting mold.
\end{abstract}

KEY WORDS: electropulsing; mold flux; crystallization; heat transfer.

\section{Introduction}

It is well acknowledged that the existence of mold fluxes is beneficial for the continuous casting process of steels, mainly due to the effects of controlling in-mold heat transfer and lubrication for the shell. ${ }^{1-3)}$ The molten flux atop of the mold would infiltrate into the gap between the initial formed shell and water-cooling copper mold, subsequently, it would solidify against the mold surface. ${ }^{4,5)}$ The solidified mold flux film in the range of $1-2 \mathrm{~mm}$ thick is generally divided into three layers induced by the existing temperature gradient between the shell and mold, i.e., a glassy layer close to the mold wall, a liquid layer close to the shell, and a crystallized layer in the middle. ${ }^{6,7)}$ Both the solid and the liquid layer would determine the in-mold heat transfer that associates with the shell surface quality and mold lubrication behavior to ensure the smoothness of casting operation. ${ }^{8,9)}$ Therefore, it is essential to study the behavior of mold flux solidification and heat transfer. In some recent years, intensive studies concerning on the heat transfer of mold flux have been developed, such as pouring experiment, ${ }^{10}$ Copper finger dip test, ${ }^{11-14)}$ Infrared emitter technique (IET), ${ }^{15,16)}$ Parallelsided plate experiment ${ }^{17,18)}$ and Mold Flux Heat Transfer Simulator (MFHTS) technique. ${ }^{19,20)}$ Especially, the MFHTS technique could simulate the heat transfer phenomena in the

\footnotetext{
* Corresponding author: E-mail: wanlin.wang@gmail.com DOI: https://doi.org/10.2355/isijinternational.ISIJINT-2018-549
}

mold and be able to compare the thermal property of different mold fluxes, which not only can simulate the actual situation of continuous casting operation, but also it is convenient and low economic cost.

The Electric Pulse Treatment (EPT) has become an infinite charm to the experts in materials science and engineering due to its simplicity, efficiency and low cost. The EPT shows a great advance in improving the microstructure, defect healing, causing recrystallization and phase transformation of metallic materials with the infliction of electric pulses at certain temperatures during the solidifications or at solid state of metallic materials. The major characteristics of the above-mentioned effects induced by EPT are summarized as follows:

(1) Improving solidification microstructure. ${ }^{21-23)}$ Qin et al. applied the electropulsing to pearlitic steel, transformation induced plasticity steel, and austenite stainless steel to refine the solidification microstructures that are difficult to achieve by other conventional thermo mechanical processes. ${ }^{21)}$ Nakada et al. found that the solidification structure of Sn$15 \% \mathrm{~Pb}$ binary alloy is transformed from dendrite to granular fine crystal due to the shear stress induced by electric current pulse in terms of the pressure gradient. ${ }^{23)}$ (2) Defect healing. ${ }^{24,26)}$ Zhou et al. applied a electric current of short duration to the steels with cracks, in this case, the cracks were partly healed and the microstructure won't get changed. ${ }^{24)}$ Wang et al. showed a new approach for self-healing with EPT due to the stimulus to trigger repairing of defective 
metals. $^{26}$ (3) Causing recrystallization. ${ }^{27-29)}$ Tang et al. applied the multiple pulses treatment (MPT) to fine copper wire, cold worked brass and Mg-3Al-1Zn (AZ31) alloy strip to optimize the microstructures and mechanical properties, and the cold worked brass achieved grain refinement due to the recrystallization associated with the increased nucleation and retarded grain growth induced by MPT. ${ }^{28)}$ (4) Phase transformation. ${ }^{30-32)}$ Zhu et al. studied electropulsing-treated (EPT) ZA22 alloy wire, and two stages of phase transformation were detected, in which the applied electropulsing accelerated phase transformation tremendously. ${ }^{32}$

Therefore, the idea to optimize the mold flux crystallization to achieve a more homogenized heat transfer behavior, as well as solidification structure of the initial solidified shell during the continuous casting process with EPT, is of great importance to be conducted. However, most of the studies mentioned above haven't included the combined effect of EPT on the initial solidification behavior in the continuous casting mold.

This paper is firstly applied a high energy electric field to the molten mold slag through two stainless steel electrodes, then study the heat transfer behavior and mold flux solidification under the influence of EPT based on the previous developed MFHTS technique. Thus an Electropulsing-assisted Mold Flux Heat Transfer Simulator technique (EPMFHTS) would be developed, with the aim to investigate the difference of heat transfer phenomenon including responding temperature, heat flux, interface thermal resistance between the mold and shell under the conditions of EPT. The crystallization extents of mold flux, such as slag film structure, crystalline phase and crystalline fraction are also discussed.

\section{Experimental Technique}

\subsection{Experimental Apparatus}

The Electropulsing-assisted Mold Flux Heat Transfer Simulator apparatus is shown in Fig. 1(a), and it mainly consists of four parts: pulse power system which provides high energy density current pulse, furnace heating system

(a)

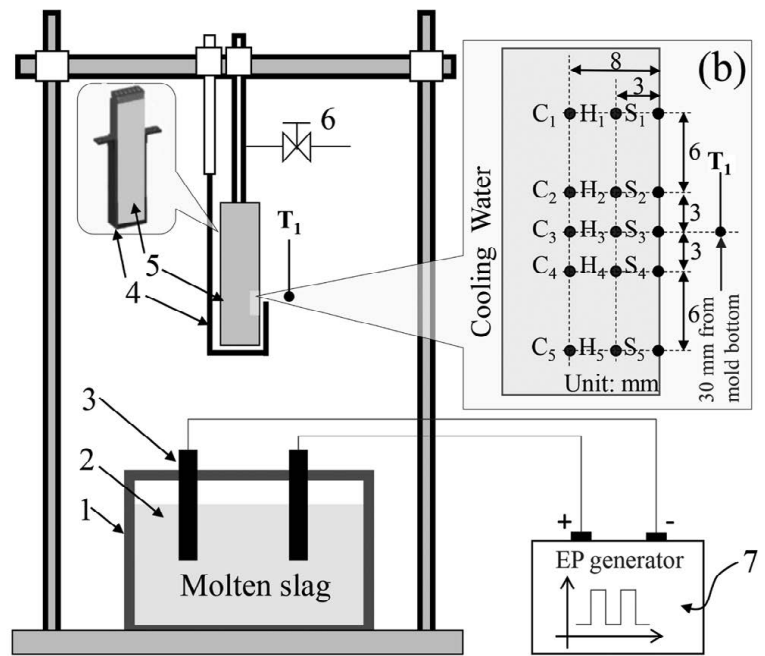

1-electric resistance furnace; 2-molten slag; 3- electrodes; 4- shield; 5-mold 6-cooling water; 7- electropulsing current generator.

Fig. 1. Schematic of the Electropulsing-assisted Mold Flux Heat Transfer Simulator apparatus and the locations of thermocouples. that can melt the mold flux, mold operation system in which the water-cooled copper mold can move in/out of the melt bath, and the data acquisition of temperature. The electropulsing (EP) generator could provide a periodic pulse current. The electrodes with the size of $450 \mathrm{~mm}$ height and 9 diameters are made from steel. The mold is manufactured with two circulating cooling water grooves inside the copper plate, and 10 thermocouples were embedded inside the mold in two columns, in which one is $3 \mathrm{~mm}$ close to the hot surface of the mold, and the other is $8 \mathrm{~mm}$ (as shown in Fig. 1(b)). Besides, one more thermocouple was attached to the mold hot face for the measurement of the temperature of the liquid mold flux. Furthermore, the sampling rate of the temperatures measurement of the thermocouple is $75 \mathrm{~Hz}$.

\subsection{Experimental Process}

The experimental process was shown in Fig. 2. Firstly, the resistance furnace with a graphite crucible placed inside was heated to $1673 \mathrm{~K}$, then $4 \mathrm{~kg}$ pre-decarburized commercial mold flux powders for the casting of a typical peritectic steels, which had been treated in a programmable furnace at $1073.15 \mathrm{~K}$ for 6 hours, were added into the crucible and got melted. The major chemical compositions of mold powders were shown in Table 1, and they were hold in the crucible at $1673 \mathrm{~K}$ for 5 minutes for the homogenization of the composition. The liquid temperature was measured by a platinum rhodium thermocouple. Then, the two steel electrodes linked to the pulse power supply device were immersed into the molten pool in parallel as shown in Fig. 2(b). Subsequently, the power supply device was run according to the preset parameters as shown in Table 2.

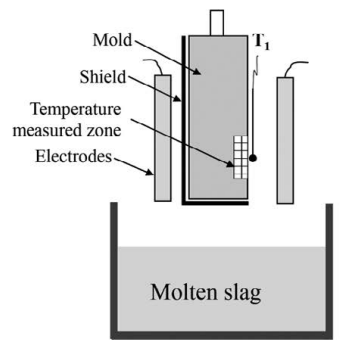

(a) Melt Formation

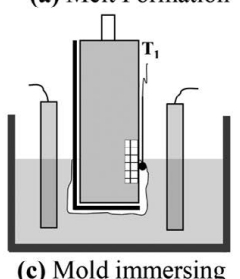

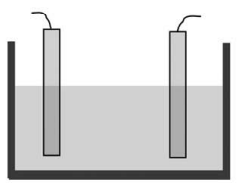

(b) Electrodes immersing

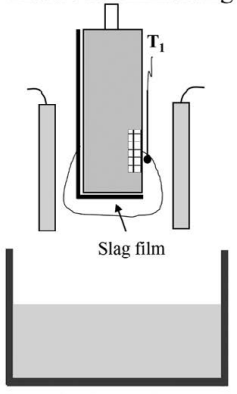

(d) Withdrawal of Mold and Electrodes
Fig. 2. Installation of experimental process diagram.

Table 1. The Main Chemical Composition of Mold Flux (wt\%).

\begin{tabular}{ccccccccc}
\hline $\mathrm{CaO}$ & $\mathrm{SiO}_{2}$ & $\mathrm{Al}_{2} \mathrm{O}_{3}$ & $\mathrm{MgO}$ & $\mathrm{Na}_{2} \mathrm{O}$ & $\mathrm{Li}_{2} \mathrm{O}$ & $\mathrm{MnO}$ & $\mathrm{BaO}$ & Basicity \\
\hline 31.5 & 26.5 & 8 & 7 & 7 & 1.8 & 7 & 3.5 & 1.19
\end{tabular}

Table 2. Electric Pulse Parameters Used in the Experiments.

\begin{tabular}{ccccc}
\hline $\begin{array}{c}\text { peak voltage } \\
(\mathrm{V})\end{array}$ & $\begin{array}{c}\text { average current } \\
(\mathrm{A})\end{array}$ & $\begin{array}{c}\text { Frequency } \\
(\mathrm{Hz})\end{array}$ & $\begin{array}{c}\text { Duration time } \\
(\mu \mathrm{s})\end{array}$ & $\begin{array}{c}\text { Treat time } \\
(\text { minute })\end{array}$ \\
\hline 30 & 11 & 100 & 120 & 10 \\
\hline
\end{tabular}


Then, the mold operation system controlled by the computer was dipped into the liquid mold flux pool as shown in Fig. 2(c). Once the mold was dipped into the molten slag bath, it would solidify against the water-cooling mold and form initial shell as it does in the casting mold. During the test, the responding temperatures were acquired by thermocouples through the data acquisition system. Finally, the pulse power supply device was turned off and the mold system was lifted out of the liquid bath as shown in Fig. 2(d). The slag film was then cooled in the air, and the complete slag film was removed from the hot surface of the copper mold, so that the slag film could be sampled at different positions of the copper mold for later analysis.

A benchmark experiment under the same condition except for EPT was conducted firstly, for the comparison of the EPT effect on the mold flux crystallization and heat transfer behavior.

\section{Results and Discussion}

\subsection{Responding Temperatures Inside the Mold}

The responding temperatures during the tests run are given in Fig. 3, where $\mathrm{H}$ represents hot side, and $\mathrm{H}_{1}$ to $\mathrm{H}_{5}$ stand for the 5 thermocouples close to the hot side of the mold (as shown in Fig. 1(b)). $\mathrm{H}_{\mathrm{N}}$ means the tests run without EPT, while $\mathrm{H}_{\mathrm{P}}$ means the test run under the EPT condition. The whole distribution of the responding temperature could be divided into four stages during the complete experimental process, in which Stage I is the dipping time from 0 to 2.5 seconds, where the temperatures are observed to increase dramatically when the mold contacts with the melt, and $\mathrm{H}_{5}$ rises to a maximum value of $371.25 \mathrm{~K}$ around 2.5 seconds.
During the Stage II, there is a sharp declining stage occurring from 2.5 to 8 seconds, and the molten mold flux begins to solidify and crystallize against the mold hot surface. Thus, it generates a certain thermal resistance between the melt and mold due to the existence of solid slag film and air gap between the solid flux film and the mold. The crystallization of mold flux results in the solidification shrinkage and introduces interfacial thermal resistance. The general heat transfer is inhibited due to the initial solidification of molten flux, so the responding temperatures decrease rapidly. In Stage III from 8 to 15 seconds, the temperature decreases further continuously, as the liquid slag solidifies constantly against the initial crystallized mold flux film, and the thermal resistance increases further. When the heat transfer steps into a relative steady state, the thermal resistance keeps stable, and the responding temperatures step into a relative steady state in Stage IV from 15 to 30 seconds.

The responding temperatures for thermocouples $\mathrm{H}_{1}$ and $\mathrm{H}_{5}$ were selected as the representatives for the comparison to investigate the effect of EPT on the heat transfer behavior of molten flux, as shown in Fig. 3(c). The general pattern of temperatures evolution for both cases shows a similar trend, and they overlap with each in Stage I. However, during the Stage II and III, the responding temperatures fall more dramatically in the case of EPT condition. It has been suggested that the particles movement in the liquid mold flux is accelerated by the electric potential ${ }^{33)}$ while applying the high energy density electric current pulse, which leads to the promotion of mold flux crystallization. Therefore, the thermal resistance in the case of EPT increases in a higher latitude, and the stable values for responding temperatures (Stage IV) in the case of EPT are relatively lower. The fur-
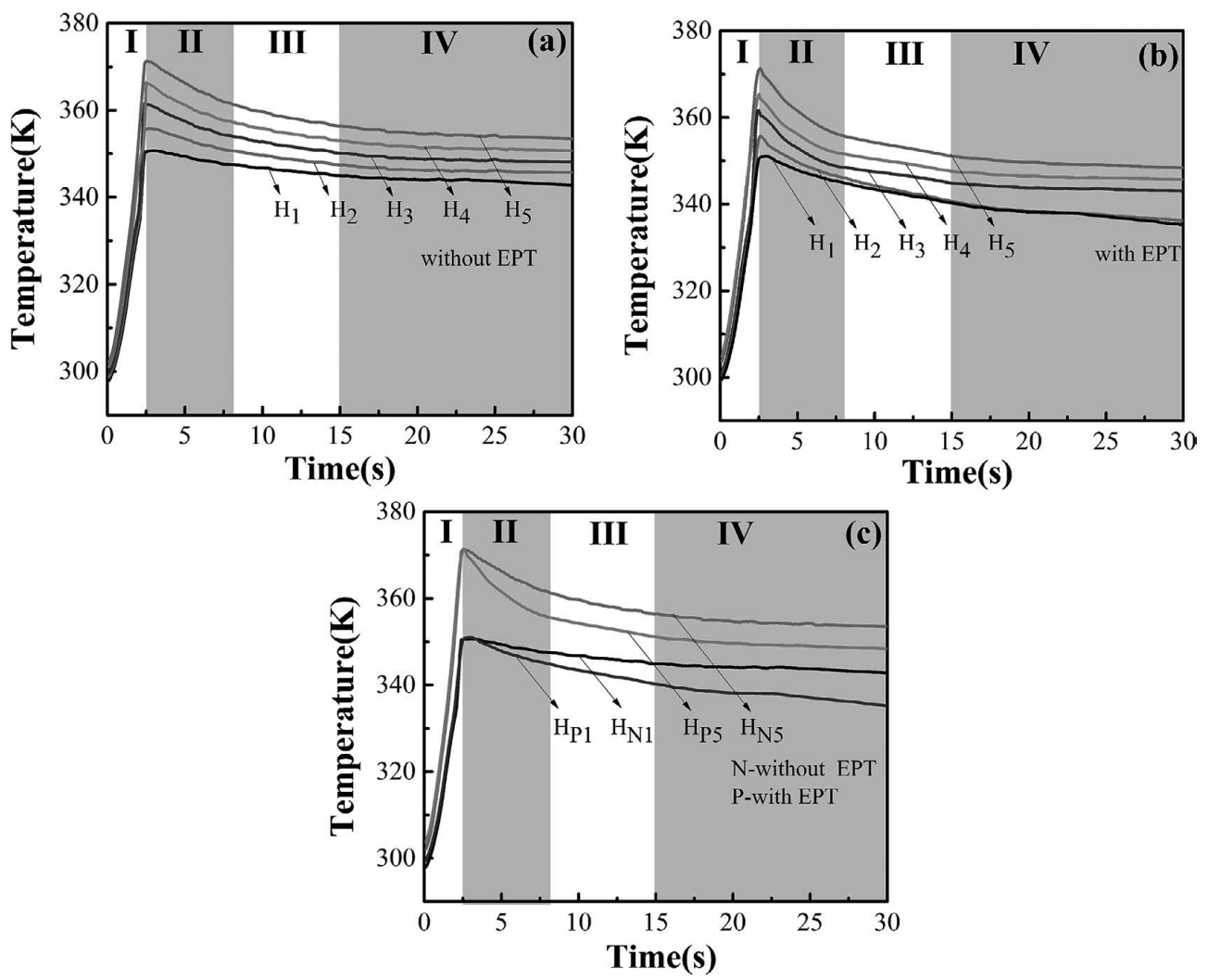

Fig. 3. Responding temperature histories of mold flux with a residence time of $30 \mathrm{~s}$ : a) blank condition; b) EPT condition; and c) comparison for both conditions. 
ther details will be given in Session 3.3.

\subsection{Heat Flux Variation Across the Mold}

The responding heat fluxes across the mold are calculated by means of the one-dimensional inverse heat conduction problem (1D-IHCP) algorithm, ${ }^{34-36)}$ as the horizontal heat transfer from the molten steel to mold is far higher than that of vertical heat transfer. For the inverse problem calculation, one-dimensional heat transfer without internal heat source can be obtained by solving the Fourier equation: $\mathrm{S}_{1}$ represents the hot surface location of the mold that is connected with the thermocouple of $\mathrm{H}_{1}$ and $\mathrm{C}_{1}$, and its heat flux value can be calculated according to the temperatures gradient measured by the thermocouples of $\mathrm{H}_{1}$ and $\mathrm{C}_{1}$. $\mathrm{S}_{\mathrm{N} 1}$ and $\mathrm{S}_{\mathrm{N} 5}$ mean the heat fluxes for $S_{1}$ and $S_{5}$ in the case of blank condition, while $\mathrm{S}_{\mathrm{P} 1}$ and $\mathrm{S}_{\mathrm{P} 5}$ mean the heat fluxes for $\mathrm{S}_{1}$ and $\mathrm{S}_{5}$ under the EPT condition.

As shown in Fig. 4, the heat fluxes show a similar variation trend as the responding temperatures in Fig. 3, in which a sharp rise occurs in Stage I from 0 to 1.1-1.4 seconds during which the copper mold is immersed into the molten pool, and the peak value reaches about $1.84 \mathrm{MW} / \mathrm{m}^{2}$, which is equivalent to an actual continuous casting process. It indicated that the initial slag film forms on the mold surface from 1.1-1.4 seconds rather than 2.5 seconds as shown in Figs. 3 and 5, the time that the responding temperature gets a maximum value. Furthermore, the heat flux at $\mathrm{S}_{5}$ also first increases followed by $\mathrm{S}_{4}, \mathrm{~S}_{3}, \mathrm{~S}_{2}$, and $\mathrm{S}_{1}$. During Stage II, there is a reduction of heat flux and the slag continuous to solidify and crystallize against the mold hot surface from 1.4 to 8 seconds. The initial solid slag film and air gap between the slag film and mold have been formed; thus, the interfacial thermal resistance increase significantly, leading to the quick drop of the heat flux in Stage II. In Stage III, the trend of heat flux decreases further with the liquid slag continuously solidifies against the initial solid slag film and the thermal resistance increases constantly from 8 to 15 seconds. When the heat transfer from the liquid mold flux to the water-cooling mold steps into a relative steady state, the thermal resistance keeps constant, and the heat flux becomes relatively stable during Stage IV from 15 to 30 seconds.

The heat flux $S_{1}$ and $S_{5}$ were selected to identify the effect of EPT on the heat flux variation across the mold, as shown in Fig. 4(c). The trend of heat flux variation is similar and they overlap with each in Stage I. During the Stage II and III, the heat flux falls more dramatically in the case of EPT, which suggests that the crystallization of the melts is more dynamic. The reason is possibly due to the accelerated particles movement in the melts by the application of highenergy electric current pulse, which is favor for the mold flux crystallization. It is obvious that the thermal resistance increases with further crystallization of mold flux, since that the radiant heat flux of the mold flux system in the crystalline state is generally lower than that in the glass state due to the influence of lattice defect and grain boundary. Other than that, the heat flux at $\mathrm{S}_{5}$ also first falls followed by the upper location like $S_{1}$ as shown in Fig. 5(c). The stable values of heat fluxes in the case of EPT are relatively lower in Stage IV, which possibly indicated the improved crystallization ratio in mold flux system. The phenomenon will be further discussed follow.

\subsection{Thermal Resistance between Slag/Mold Interface}

Figure 6 shows the evolvement of responding tempera-
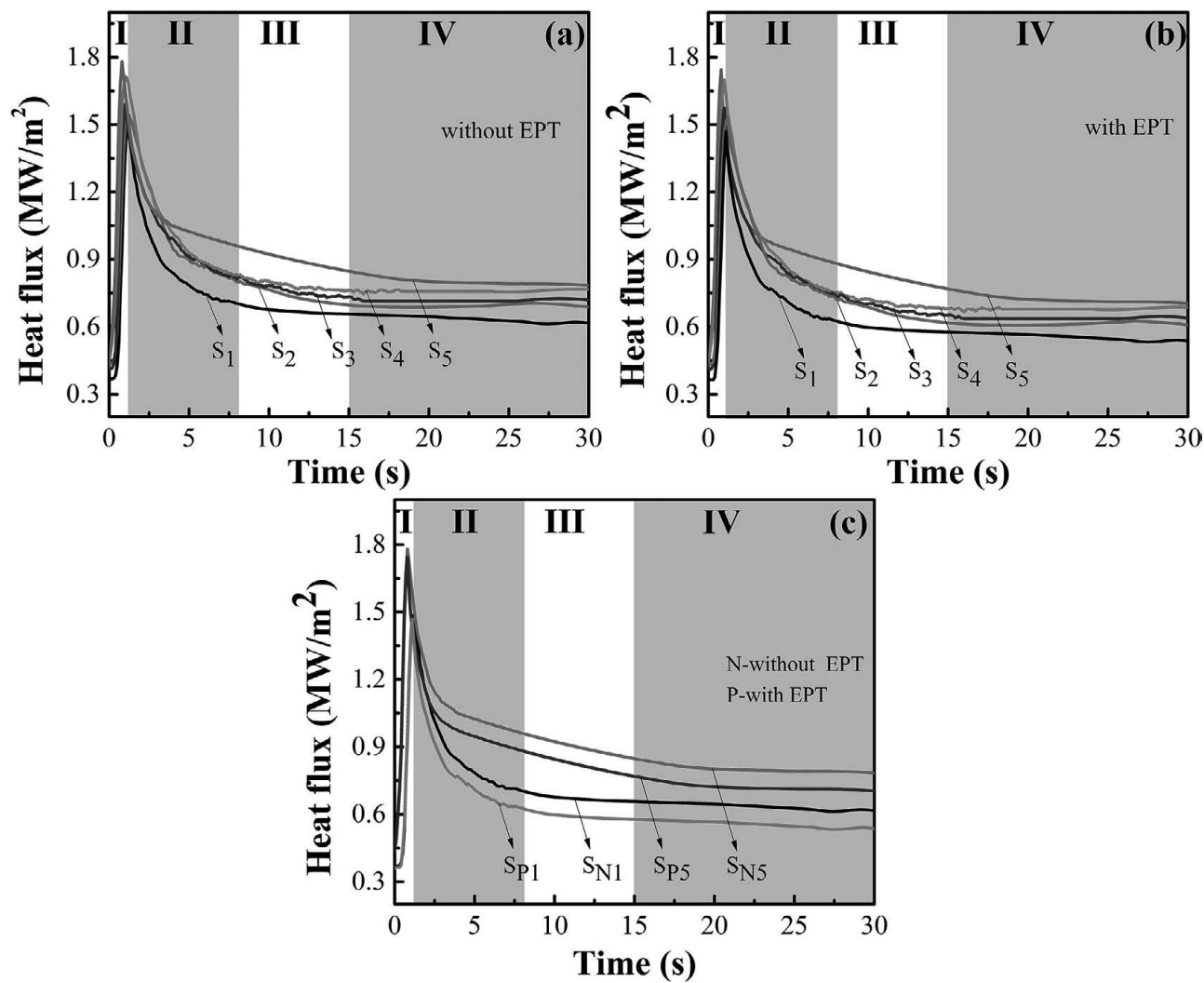

Fig. 4. Heat flux curves across the mold surface: a) blank condition; b) EPT condition; and c) comparisons under both conditions. 

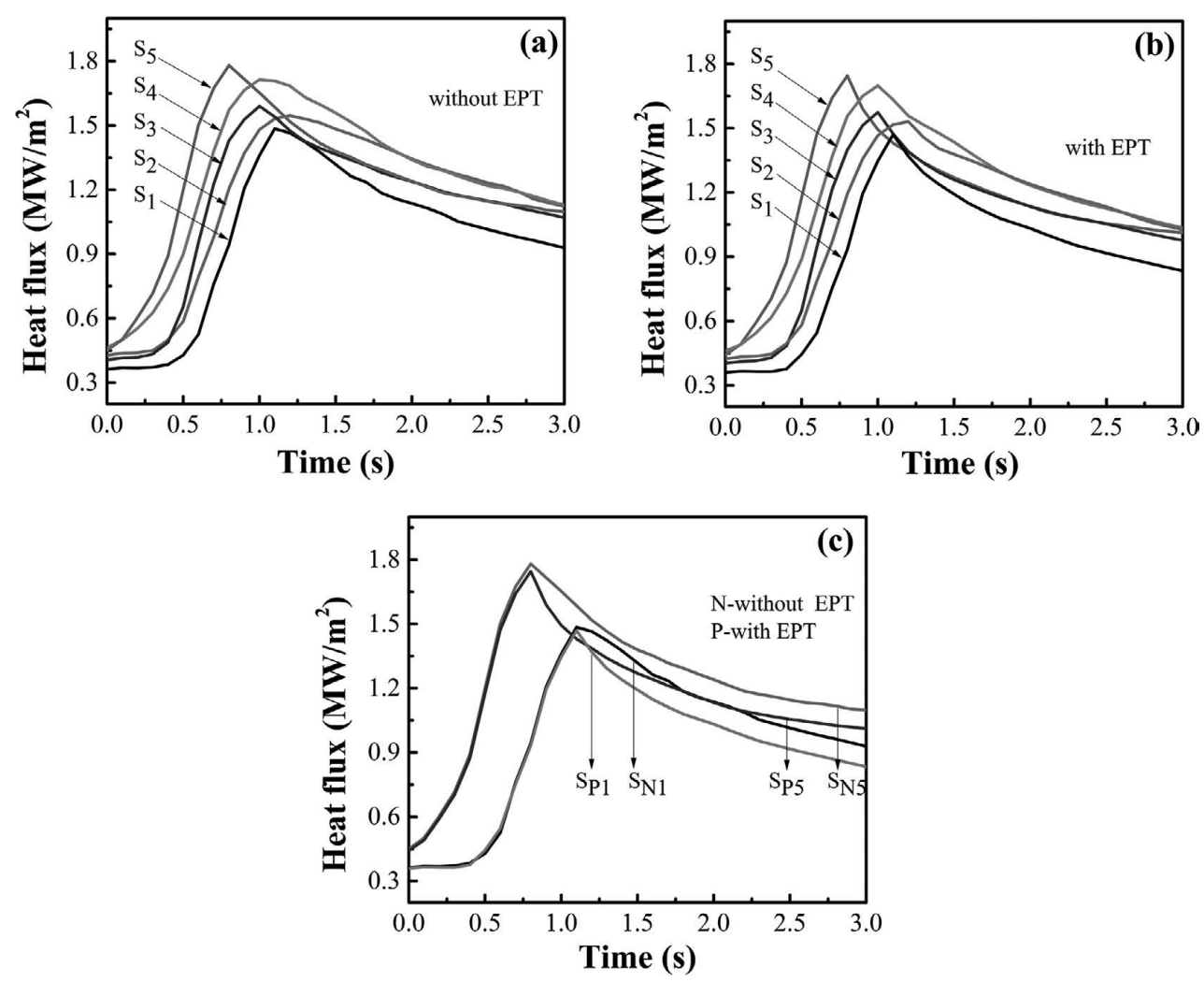

Fig. 5. Initial responding heat flux histories during the experiment: a) blank condition; b) EPT condition; and c) comparisons under both conditions.
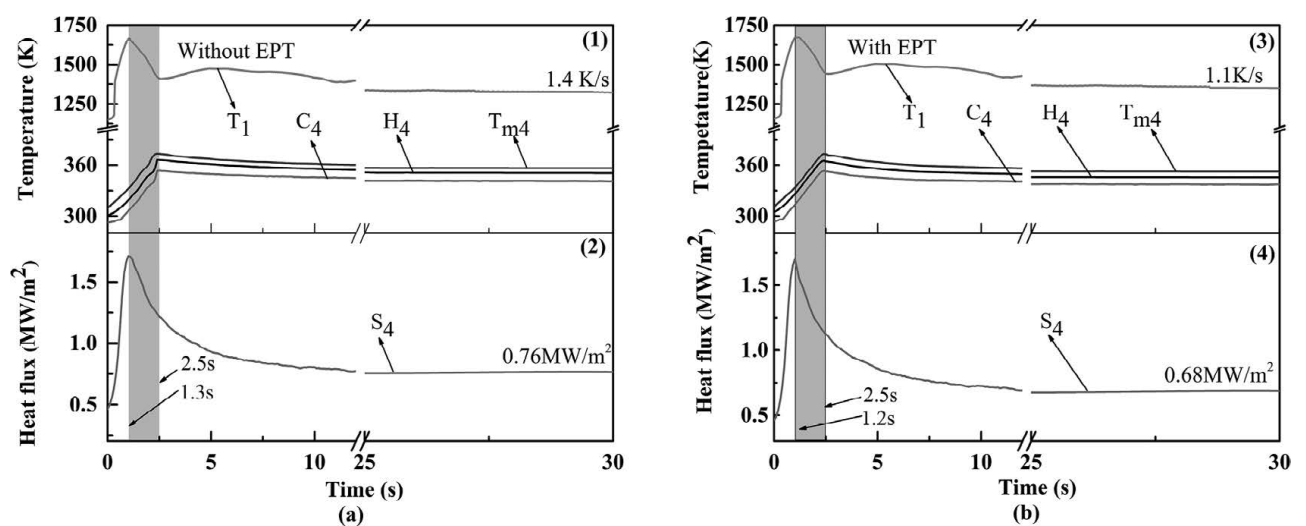

Fig. 6. The evolvement of responding temperatures and heat fluxes across the mold: a) blank condition; and b) EPT condition.

tures and heat fluxes across the mold during the tests, where $\mathrm{T}_{1}$ represents the temperature inside the liquid slag bath that $3 \mathrm{~mm}$ away horizontally from the hot surface of the mold. $\mathrm{H}_{4}$ and $\mathrm{C}_{4}$ stand for the 4 th row temperatures as shown in Fig. 1. $\mathrm{Tm}_{4}$ and $\mathrm{S}_{4}$ are the responding temperature and heat flux at the hot surface of the mold obtained through the one-dimensional inverse algorithm. The variation of $\mathrm{H}_{4}$, $\mathrm{C}_{4}, \mathrm{Tm}_{4}$ and $\mathrm{S}_{4}$ has the similar trend as the ones described in Figs. 3, 4. The temperature $\mathrm{T}_{1}$ for both cases increases rapidly when the mold is immersed into the molten pool and reaches the maximum value around 1.2-1.3 seconds which is the same time that heat flux picks up in Fig. 4. It indicates that the EPMFHTS system starts to be heated up and the initial solidified shell forms against the mold hot surface at around 1.2-1.3 seconds. Then, $\mathrm{T}_{1}$ decreases sharply due to cooling effect by the cold mold to the molten mold flux till 2.5 seconds, at which the initial shell has formed. After 2.5 seconds, $\mathrm{T}_{1}$ begins to rise following by continuous decrease slightly, which can be explained that the initial slag film partly happened to be re-melted under the continuous heating of molten pool and the crystals were broken down and moved toward the liquid pool. Then $T_{1}$ gradually reduced as the cooling potential from the mold dominates the heat transfer process, and the molten bath was continuously cooled. Finally, $\mathrm{T}_{1}$ reaches a quasi-steady state and it remains relatively constant. As a contrast, the final stable value in EPT condition is lower than blank case, where the cooling rate is $1.4 \mathrm{~K} / \mathrm{s}$ for blank condition and $1.1 \mathrm{~K} / \mathrm{s}$ for the case of EPT condition that determined from the curve in the quasi-steady stage (from 25 to 30 seconds), which suggests that the enhanced crystallization in the case of EPT would bring a higher thermal resistance that leading to a lower cooling rate.

The SEM images for the mold flux films cross sections 
got from both conditions are shown in Fig. 7, a crystalline layer contacting with the mold hot face could be found and the crystalline layer thickness after experiment is around 0.88 and $1.16 \mathrm{~mm}$ respectively. It is obvious that the crystalline layer thickness in case of EPT is thicker due to the enhanced crystallization ability induced by the accelerated movement of the ions' cluster (e.g., $\mathrm{Ca}^{2+}, \mathrm{Na}^{+}$, etc.) and molecular units while applying the electric potential. The direction and velocity of the movement are determined by the configuration of electrical domains caused by the applied electric potential. ${ }^{37)}$ The thermocouple $\mathrm{T}_{1}$ schematically shown as red dot in Fig. 7 is embedded in crystalline layer after experiment, and this means that the thermocouple $T_{1}$ measures the solid crystalline layer temperature in quasisteady state after 25 seconds.

In order to get the crystallization temperature $T_{\text {sol }}$ for above sample, the single hot thermocouple technique (SHTT) has been applied in this study, and the details has been given in previous studies. ${ }^{19,20)}$ The temperature control profile and the initial crystallization photos are shown in Fig. 8, where the cooling rates are 1.4 and $1.1 \mathrm{~K} / \mathrm{s}$ that determined from $T_{1}$ temperatures curves in equilibrium stage in Fig. 6. It can be clearly seen from the photos that the $\mathrm{T}_{\text {sol }}$ at the cooling rate of $1.4 \mathrm{k} / \mathrm{s}$ is $1337.15 \mathrm{~K}$ (blank case), and $1359.15 \mathrm{~K}$ for the cooling rate of $1.1 \mathrm{k} / \mathrm{s}$ (EPT case). The higher crystallization temperature in EPT case indicates that lower cooling rate would promote the initiation of crystallization.

A mathematic model is applied to investigate the interfa-

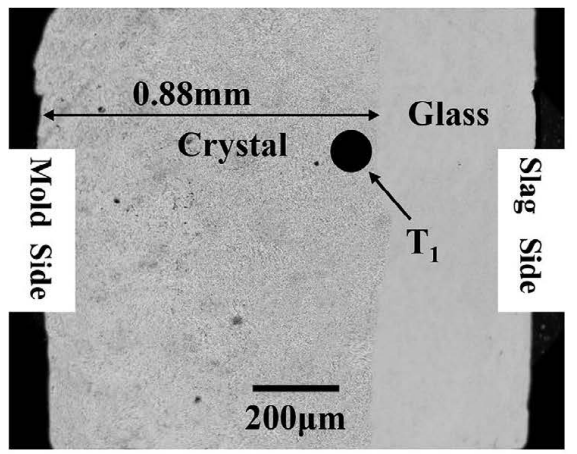

(a) cial thermal resistance of slag/mold interface $\left(R_{\text {int }}\right)$ at steady state, and temperature data shown in Fig. 6 after $25 \mathrm{~s}$ is used for the calculation. The following assumptions were made as previous work ${ }^{19,20)}$ for development of the model: (1) heat transfer from the mold flux to the water-cooled copper mold is under steady state; (2) heat transfer in vertical direction is neglected relative to that of horizontal one; and (3) the total heat flux consisted of conductive and radiative heat fluxes.

Figure 9 shows the calculated region within the copper mold and the melts, where $T_{m 4}$ represents the hot surface temperature of the mold calculated through the temperature gradient between $\mathrm{H}_{4}$ and $\mathrm{C}_{4}$ in the mold. The mold flux film is then divided into two regions (Region 1 and 2) by thermocouple $T_{1}$, where the subscripts 1 and 2 represent the properties in Region 1 and 2, respectively.

Therefore, the heat flux at steady state across solid mold flux can be expressed as

$$
\begin{gathered}
q_{\text {tot }}=q_{\text {cond }}+q_{\text {rad }} \ldots \ldots \ldots \\
q_{\text {cond } 2}=K_{\text {cond }} \frac{T_{\text {sol }}-T_{1}}{d_{2}} \ldots . \\
q_{r a d 2}=\frac{n^{2} \sigma\left(T_{s o l}^{4}-T_{1}^{4}\right)}{0.75 \alpha d_{2}+2 \varepsilon_{c r y}^{-1}-1} .
\end{gathered}
$$

where $q_{\text {tot }}$ is the heat flux calculated by $1 \mathrm{D}$-IHCP at steady state in Fig. 6. $q_{\text {cond }}$ and $q_{\text {rad }}$ are conductive and radiative heat fluxes, respectively. $K_{\text {cond }}$ is the thermal conductiv-

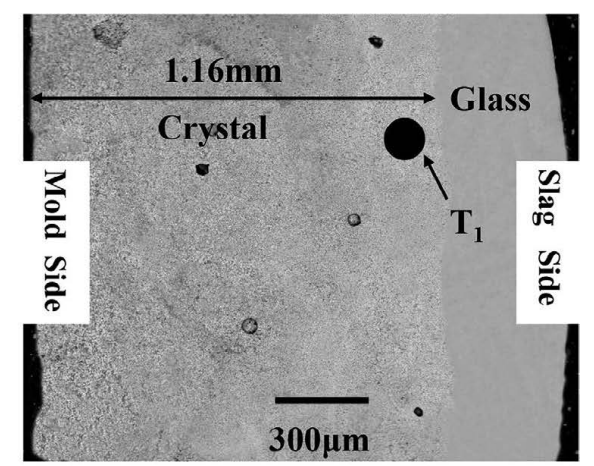

(b)

Fig. 7. SEM photograph of the cross section of mold flux film $3 \mathrm{~mm}$ below the liquid level: a) blank condition; and b) EPT condition.
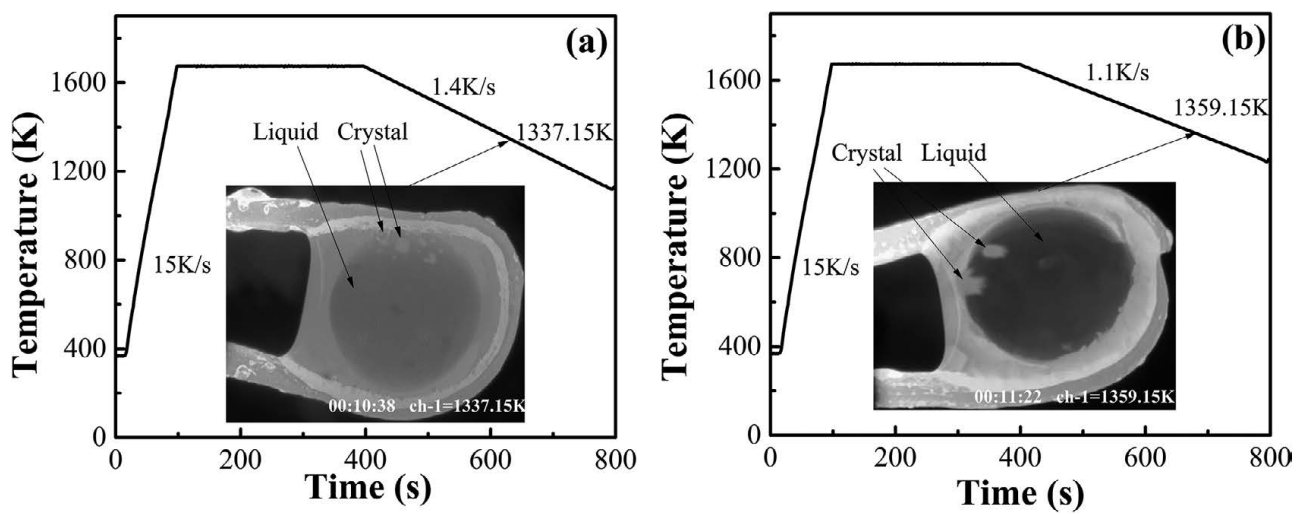

Fig. 8. Thermal profile for the study of the solidification temperature of mold flux during continuous cooling period: a) blank condition; and b) EPT condition. 


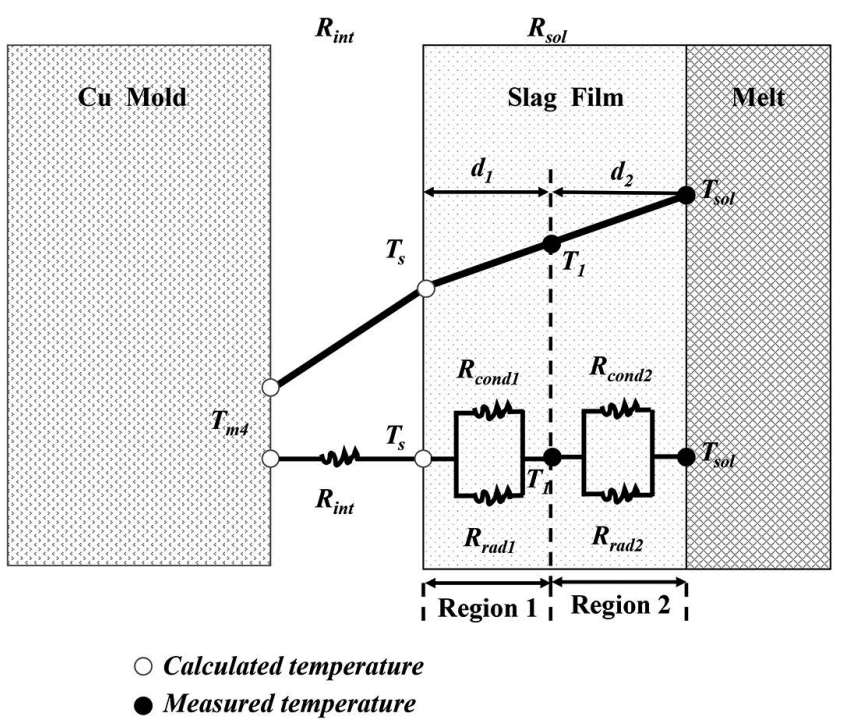

Fig. 9. Model of temperature distribution and thermal resistance calculation.

ity coefficient of the crystallization slag film, and $T_{\text {sol }}$ is the interfacial temperature between the crystal and liquid layers that equals the crystallization temperature. $T_{1}$ is the temperature measured by the extra thermocouple $\mathrm{T}_{1} . d_{2}$ is the thickness between $T_{1}$ and solid flux/melt surface in this model, $n$ is the refractive index that is equal to $1.6,{ }^{38,39)} r$ is the Stefan-Boltzmann constant, at $5.6705 \times 10^{-8} \mathrm{~W}\left(\mathrm{~m}^{-2}\right.$ $\mathrm{K}^{-4}$ ), $\varepsilon$ represents the emissivity, as 0.7 for crystalline mold flux, ${ }^{40)}$ and $\alpha$ is the absorption coefficient of solid mold flux, around $4500 \mathrm{~m}^{-1}$ for crystal. ${ }^{15)}$

Therefore, the conductive heat flux $q_{\text {cond }}$ and radiative heat flux $q_{\text {rad }}$ at steady state across solid mold flux layer can also be written as Eqs. (4) and (5): ${ }^{16,38)}$

$$
\begin{gathered}
q_{c o n d 1}=K_{\text {cond }} \frac{T_{1}-T_{s}}{d_{1}} \ldots . \\
q_{r a d 1}=\frac{n^{2} \sigma\left(T_{1}^{4}-T_{s}^{4}\right)}{0.75 \alpha d_{1}+2 \varepsilon_{c r y}^{-1}-1}
\end{gathered}
$$

where $T_{s}$ is the slag surface temperature and $d_{l}$ is the thickness from the thermocouple $T_{1}$ to slag film surface as shown in Fig. 9. The crystallization temperature $T_{\text {sol }}$ is obtained through the SHTT tests discussed above.

$R_{t o t}$ is the sum of $R_{i n t}$ and flux film resistance, $R_{\text {sol }}$, as follows:

$$
\begin{gathered}
R_{\text {int }}=\frac{T_{s}-T_{m 4}}{q_{t o t}} \\
R_{t o t}=R_{\text {int }}+R_{\text {sol }} \\
R_{\text {sol }}=\frac{T_{\text {sol }}-T_{s}}{q_{t o t}}
\end{gathered}
$$

Thus, the thermal conductivity coefficient of the crystallization slag film $K_{\text {cond }}$ can be calculated using Eqs. (1) through (3). Substitute the calculated $K_{\text {cond }}$ into Eq. (4), and substitute Eqs. (4) and (5) into Eqs. (1) and (6). Then

\begin{tabular}{|c|c|c|c|}
\hline \multirow{7}{*}{$\begin{array}{l}\text { Calculated } \\
\text { parameter }\end{array}$} & parameter & without EPT & with EPT \\
\hline & $\alpha\left(\mathrm{m}^{-1}\right)$ & 2054.30 & 2077.80 \\
\hline & $K_{\text {cond }}\left(\mathrm{W} \mathrm{m}^{-1} \mathrm{~K}^{-1}\right)$ & 1.66 & 1.74 \\
\hline & $T_{s}(\mathrm{~K})$ & 1024.70 & 1011.20 \\
\hline & $R_{\text {int }}\left(\mathrm{m}^{2} \mathrm{~K} \mathrm{~W}^{-1}\right)$ & $8.80 \times 10^{-4}$ & $9.69 \times 10^{-4}$ \\
\hline & $R_{s o l}\left(\mathrm{~m}^{2} \mathrm{~K} \mathrm{~W}^{-1}\right)$ & $4.11 \times 10^{-4}$ & $5.12 \times 10^{-4}$ \\
\hline & $R_{\text {tot }}=R_{\text {int }}+R_{s}$ & $12.91 \times 10^{-4}$ & $14.81 \times 10^{-4}$ \\
\hline \multirow{9}{*}{$\begin{array}{l}\text { Knowing } \\
\text { parameter }\end{array}$} & $d_{l}(\mathrm{~m})$ & $0.84 \times 10^{-3}$ & $1.13 \times 10^{-3}$ \\
\hline & $d_{1}+d_{2}(\mathrm{~m})$ & $0.88 \times 10^{-3}$ & $1.16 \times 10^{-3}$ \\
\hline & $T_{l}(\mathrm{~K})$ & 1322.95 & 1350.15 \\
\hline & $T_{s o l}(\mathrm{~K})$ & 1337.15 & 1359.15 \\
\hline & $T_{m 4}(\mathrm{~K})$ & 356.29 & 352.30 \\
\hline & $q_{t o t}\left(\mathrm{MW} / \mathrm{m}^{2}\right)$ & 0.76 & 0.68 \\
\hline & $n$ & \multicolumn{2}{|c|}{1.60} \\
\hline & $\sigma\left(\mathrm{W} \mathrm{m}^{-2} \mathrm{~K}^{-4}\right)$ & \multicolumn{2}{|c|}{$5.6705 \times 10^{-8}$} \\
\hline & $\varepsilon$ & \multicolumn{2}{|c|}{0.70} \\
\hline
\end{tabular}
solve the nonlinear equations of Eqs. (1) and (6) by Newton iterative method to obtain $R_{\text {int }}$ and $T_{s}$. The known parameters
Table 3. Parameters in Interfacial Thermal Resistance Calculation.

used in the calculation and the calculated results are listed in Table 3.

In case of the blank condition, $T_{s}$ is equal to $1024.70 \mathrm{~K}$, the interface thermal resistance is $8.80 \times 10^{-4} \mathrm{~m}^{2} \mathrm{~K} / \mathrm{W}$, the slag film thermal resistance is $4.11 \times 10^{-4} \mathrm{~m}^{2} \mathrm{~K} / \mathrm{W}$ and the total thermal resistance is $12.91 \times 10^{-4} \mathrm{~m}^{2} \mathrm{~K} / \mathrm{W}$. In case of the EPT, $T_{s}$ is equal to $1011.20 \mathrm{~K}$, the interface thermal resistance is $9.69 \times 10^{-4} \mathrm{~m}^{2} \mathrm{~K} / \mathrm{W}$, the slag film thermal resistance is $5.12 \times 10^{-4} \mathrm{~m}^{2} \mathrm{~K} / \mathrm{W}$ and the total thermal resistance is $14.81 \times 10^{-4} \mathrm{~m}^{2} \mathrm{~K} / \mathrm{W}$ respectively. Moreover, $K_{\text {cond }}$ is 1.66 and $1.74 \mathrm{~W} \mathrm{~m}^{-1} \mathrm{~K}^{-1}$ for tests without and with EPT respectively, which is in the range of the results reported by Nakada. ${ }^{40)} \alpha$ is 2054.30 and $2077.80 \mathrm{~m}^{-1}$ in cases of without and with EPT respectively, which agrees with the values reported by Yoon. ${ }^{41)}$ It could be observed that the interfacial thermal resistance plays significant role in the control of heat transfer behavior in the casting mold. It also could be found that the values for $R_{\text {int }}$ and $R_{\text {tot }}$ in the case of EPT are higher than the blank case, which will be further discussed in session 3.4.

\subsection{Microstructure of Mold Flux Film}

The cross sections of the slag films under the blank and the EPT conditions are taken after the experiments, and their SEM photographs are shown in Fig. 10. The slag films are both divided into three regions: a fine crystalline layer (I) formed close to the mold surface due to the high cooling rate from the mold, a glassy (liquid) layer (III) due to the fast cooling of the liquid directly exposed in the air after the experiment and a coarse grain layer (II) due to the smaller temperature gradient. The size of the newly formed crystals in region $\mathrm{A}$ is relatively fine compared with region $\mathrm{B}$, due to a high cooling from the mold, and then grows to coarse dendrites in region $\mathrm{B}$ with the reduction of temperature gradient. It could be distinctly found that the crystals in case of EPT are much denser and smaller in size in region A to $\mathrm{B}$ which indicates the application of electric current pulse 

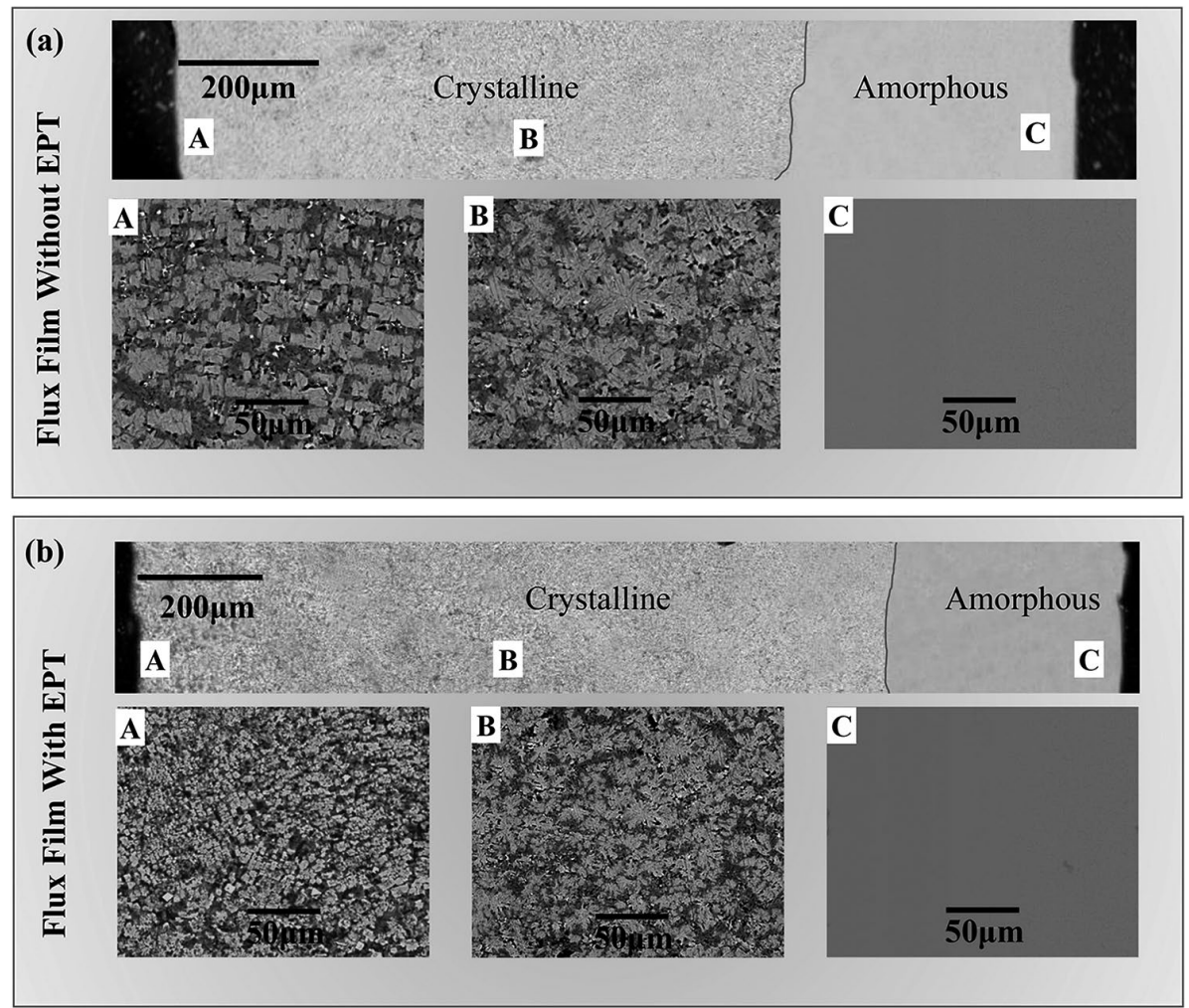

Fig. 10. SEM micrographs of mold flux film $3 \mathrm{~mm}$ below the liquid level: a) blank condition; and b) EPT condition.

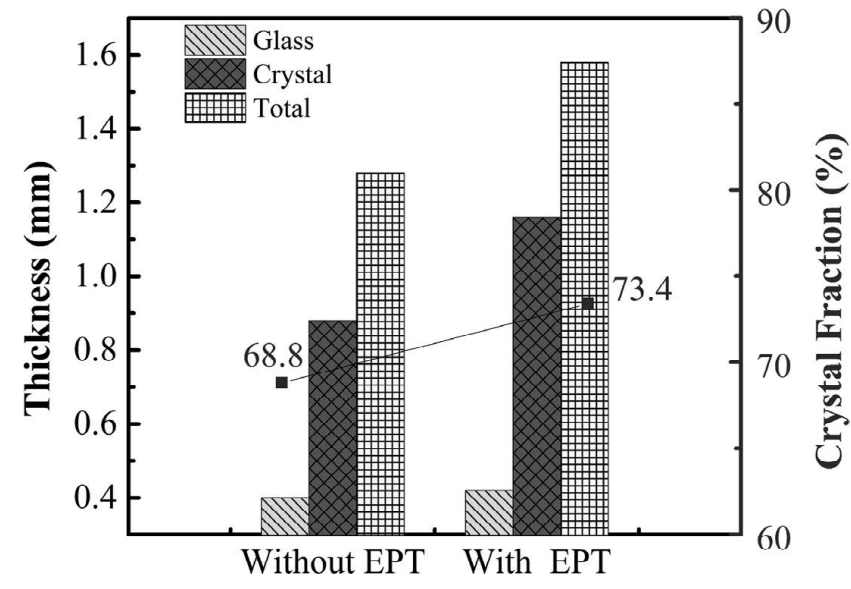

Fig. 11. The crystallization degree of mold flux film under both conditions.

promotes the crystallization capacity by enhancing particle mobility in molten slag and also refines the crystals size.

The thickness and crystallization fraction of the mold flux film are shown in Fig. 11 according to statistics. As expected, the crystalline layer thickness increases from 0.88 to $1.16 \mathrm{~mm}$, and the crystal fraction in the samples increases from $68.8 \%$ to $76.3 \%$ with the application of EPT. A thick crystalline layer with small crystalline size would improve the interfacial and total thermal resistance during the heat transfer process, as there would be a large air gap (between the solid mold flux film and cooling mold) formed due to the further shrinkage of the solid mold flux during mold flux crystallization. Also a large amount of radiative heat flux would be reflected at the boundaries of the crystals. Therefore, the interfacial and total thermal resistance would increase with the application of EPT.

\section{Conclusions}

A novel Electropulsing-assisted Mold Flux Heat Transfer Simulator technique (EPMFHTS) was developed to investigate the effect of EPT on the crystallization and heat transfer behavior of mold flux in the casting mold in this study. The major conclusions are summarized as follows:

(1) The variation pattern of responding temperatures and heat fluxes shows nearly the same trend that could be divided into four stages during the complete experimental process: rapidly rising, sharp dropping, gradually reducing and getting stable. The general evolutions of temperatures and heat fluxes overlap in Stage I for both blank and EPT cases. However, the reduction rate for temperature and heat flux is significantly higher in Stage II-III under the EPT condition, due to the increased thermal resistance resulted from the enhancement of the crystallization of the mold flux. The stable values for both temperatures and heat fluxes were relatively smaller in Stage IV for the case of EPT, which is also related to the larger crystalline fraction of the mold flux induced by the electric pulse.

(2) The total and interfacial thermal resistances of mold flux in the final relatively steady state were studied, and they are $12.91 \times 10^{-4} \mathrm{~m}^{2} \mathrm{~K} / \mathrm{W}\left(R_{\text {tot }}\right)$ and $8.80 \times 10^{-4} \mathrm{~m}^{2} \mathrm{~K} / \mathrm{W}\left(R_{\text {int }}\right)$ in the blank benchmark case. However, $R_{t o t}$ increases to $14.81 \times 10^{-4} \mathrm{~m}^{2} \mathrm{~K} / \mathrm{W}$, and $R_{\text {int }}$ reaches $9.69 \times 10^{-4} \mathrm{~m}^{2} \mathrm{~K} / \mathrm{W}$ in the case of EPT. The improved total and interfacial thermal resistance in EPT condition is due to the enhancement of the solid mold flux crystallization, where the crystalline layer thickness and the crystal fraction increases from 0.88 
to $1.16 \mathrm{~mm}$, from $68.8 \%$ to $76.3 \%$, respectively.

(3) The mold flux film formed a fine crystalline layer against the copper mold, and a coarse crystalline phase towards the liquid. The microstructure photos show that the crystallization fraction is improved and also the crystals size has been refined in the case of EPT. Above results suggest that EPT does effectively enhance the mold flux crystallization and refine crystals size, which has the great potential to be applied in the continuous casting mold for the homogenization of the heat transfer behavior during the initial molten steel solidification.

\section{Acknowledgments}

The financial support from the National Natural Science Foundation of China (51661130154, U1760202) and the Newton Advanced Fellowship (NA150320) are greatly acknowledged.

\section{REFERENCES}

1) K. Mills and A. Fox: Trans. Iron Steel Inst. Jpn., 43 (2003), 1479.

2) K. Mills, A. Fox, Z. Li and R. Thackray: Ironmaking Steelmaking, 32 (2005), 26.

3) Y. Meng and B. Thomas: Metall. Mater. Trans. B, 34 (2003), 707.

4) Y. Meng and B. Thomas: Metall. Mater. Trans. B, 34 (2003), 685.

5) H. Nakada, M. Susa, Y. Seko, M. Hayashi and K. Nagata: ISIJ Int., 48 (2008), 446.

6) Y. Meng and B. Thomas: ISIJ Int., 46 (2006), 660.

7) R. Saraswat, D. Maijer, P. Lee and K. Mills: ISIJ Int., 47 (2007), 95.

8) J. Yang, X. Meng, N. Wang and M. Zhu: Metall. Mater. Trans. B, 48 (2017), 1230

9) M. Hanao and M. Kawamoto: ISIJ Int., 48 (2008), 180.

10) H. Shibata, K. Kondo, M. Suzuki and T. Emi: ISIJ Int., 36 (1996), 179.

11) L. Strezov and J. Herbertson: ISIJ Int., 38 (1998), 959.

12) N. Machingawuta, S. Bagha and P. Grieveson: Proc. 74th Steelmaking Conf., ISS-AIME, Warrendale, PA, (1991), 163.
13) G. Wen, P. Tang, B. Yang and X. Zhu: ISIJ Int., 52 (2012), 1179.

14) G. Wen, S. Sridhar, P. Tang, X. Qi and Y. Liu: ISIJ Int., 47 (2007), 1117.

15) W. Wang and A. Cramb: ISIJ Int., 45 (2005), 1864.

16) W. Wang, L. Zhou and K. Gu: Met. Mater. Int., 16 (2010), 913.

17) J. Cho, T. Emi, H. Shibata and M. Suzuki: ISIJ Int., 38 (1998), 834.

18) R. Scheel and W. Korte: Metall. Plant Technol., 6 (1987), 22.

19) Y. Liu, W. Wang, F. Ma and H. Zhang: Metall. Mater. Trans. B, 46 (2015), 1419.

20) F. Ma, Y. Liu, W. Wang and H. Zhang: Metall. Mater. Trans. B, 46 (2015), 1902.

21) R. Qin, A. Rahnama, W. Lu, X. Zhang and B. Elliott-Bowman: Mater. Sci. Technol., 30 (2014), 1040

22) A. K. Misra: Metall. Trans. A, 16 (1985), 1354.

23) M. Nakada, Y. Shiohara and M. Flemings: ISIJ Int., 30 (1990), 27.

24) Y. Zhou, J. Guo, M. Gao and G. He: Mater. Lett., 58 (2004), 1732.

25) H. Wang, G. Song and G. Tang: Mater. Sci. Eng. A, 662 (2016), 456.

26) H. Song, Z. Wang and X. He: Sci. Rep., 7 (2017), 1.

$27)$ Z. Xu, G. Tang, S. Tian and J. He: Mater. Sci. Eng. A, 424 (2006), 300.

28) Y. Zhou, S. Xiao and J. Guo: Mater. Lett., 58 (2004), 1948.

$29)$ Z. Xu, G. Tang, F. Ding, S. Tian and H. Tian: Appl. Phys. A, 88 (2007), 429.

30) D. Ben, H. Yang, Y. Ma, X. Shao, J. Pang and Z. Zhang: Mater. Sci. Eng. A, 725 (2018), 28.

31) Y. Zhou, J. Guo, W. Zhang and G. He: J. Mater. Res., 17 (2002), 3012.

32) Y. Zhu, T. Sandy, W. Lee, X. Liu, Y. Jiang and G. Tang: J. Mater. Res., 24 (2011), 2661.

33) S. Riaz: Ironmaking Steelmaking, 39 (2013), 409.

34) A. Badri, T. Natarajan, C. Snyder, K. Powers, F. Mannion and A. Cramb: Metall. Mater. Trans. B, 36 (2005), 355.

35) H. Zhang, W. Wang, D. Zhou, F. Ma, B. Lu and L. Zhou: Metall. Mater. Trans. B, 45 (2014), 1038.

36) F. Neumann: 79th Steelmaking Conf. Proc., ISS, Warrendale, PA, (1996), 249.

37) X. Zhang and R. Qin: Sci. Rep., 5 (2015), 1.

38) S. Ozawa, M. Susa, T. Goto, R. Endo and K. Mills: ISIJ Int., 46 (2006), 413.

39) K. Gu, W. Wang, J. Wei, H. Matsuura, F. Tsukihashi, I. Sohn and D. Min: Metall. Mater. Trans. B, 43 (2012), 1393.

40) H. Nakada, M. Suza, Y. Seko, M. Hayashi and K. Nagata: ISIJ Int., 48 (2008), 446.

41) D. Yoon, J. Cho and S. Kim: Metall. Mater. Trans. B, 48 (2017), 1. 